DANIELA KERN

CLAUDIA ZIMMER

DE CERQUEIRA CEZAR

FERNANDA BULEGON GASSEN

HELENE GOMES SACCO

MARINA BORTOLUZ POLIDORO

VIVIANE GIL ARAÚJO

[」

Revista-Valise: da criação à experiência de edição

\title{
RESUMO
}

Este artigo visa compartilhar as reflexões empreendidas durante o processo de preparação, experiência de criação e desenvolvimento da Revista-Valise, periódico acadêmico, administrado por discentes do Programa de Pós-Graduação em Artes Visuais da Universidade Federal do Rio Grande do Sul, focado na área de Artes Visuais e de edição semestral. São apontados os passos e as etapas da construção da revista, tais como os objetivos do projeto, a formação da equipe editorial, delimitação de escopo, tutoriais, convite a pareceristas, abertura de edital, e recebimento e distribuição dos artigos para leitura e avaliação por pares.

Pesquisa em artes visuais. Periódicos científicos. Revista-Valise. 


\section{REVISTA-VALISE: DA CRIAÇÃO À EXPERIÊNCIA DE EDIÇÃO}

\section{Apresentação}

Iniciativa do corpo discente do PPGAV/UFRGS, a Revista-Valise é um espaço para a publicação de artigos, entrevistas, notas de leitura, traduções e resumos de tese que tem por objetivo principal a divulgação de pesquisas em âmbito de pós-graduação stricto sensu, realizadas por pós-graduandos ou mesmo pós-graduados, no campo das Artes Visuais e áreas afins. A Revista-Valise também prevê a publicação de um ensaio visual, para cada uma de suas edições, obtido por meio de convite a artistas. Reservou-se igualmente um espaço para artigo de pesquisador convidado, com solicitação direta ao autor, admitido na forma de colaboração especial à publicação. As demais participações pressupõem submissões online, sem definição antecipada de número máximo de aceites, ficando a extensão de cada edição sujeita ao volume de artigos semestralmente aprovados por meio do processo de avaliação duplo-cego.

Diante da ampliação do campo das Artes Visuais, a Revista-Valise abrange igualmente os desvios para outras áreas do conhecimento que partem do campo da arte. Neste sentido, é importante assinalar o intenso envolvimento das artes visuais com áreas correlatas, fato que tem apresentado a permeabilidade das referências teóricas, ativado discussões potentes e promovido pontos de intersecção entre práticas e projetos distintos.

A proposta para a elaboração da Revista-Valise foi lançada durante uma reunião discente do PPGAV/UFRGS, realizada no segundo semestre de 2010, quando foi formada a equipe responsável por redigir a proposta a ser encaminhada à Comissão de Pós-Graduação (Compós). Na ocasião, foi colocada em pauta a necessidade de implementação de um projeto que fomentasse a publicação científica pelos discentes de mestrado e doutorado em âmbito nacional, prática de fundamental importância para a divulgação das pesquisas desenvolvidas.

A elaboração do projeto foi o próximo passo. Assim, após tramitar pela Compós, iniciamos a fase de elaboração efetiva da revista, estruturando seu foco/escopo e seus meios de implementação.

Para elaborar o nome da revista, partimos do termo palavra-valise, surgido em um encontro entre Alice e Humpty Dumpty, personagens de Lewis Carroll. No livro Alice 
no País do Espelho, Carrol, por meio de Humpty Dumpty, apresenta à Alice o sentido do termo: "[...] é uma palavra braquilógica, como se fosse uma maleta em que você guarda ao mesmo tempo os artigos de toalete e uma muda de roupa íntima. Há dois significados empacotados em uma palavra só” (Carroll, 2008, p. I 20). Do interesse pelo desdobramento morfológico da palavra-valise surgiu o nome Revista-Valise, pensado como um novo componente que nasce do encontro das duas palavras distintas. Tal imagem pode ser tomada como metáfora do objetivo da Revista-Valise: o de acolher produções e perspectivas diversas, compartilhadas em um mesmo ambiente com vistas à incorporação de novos sentidos.

Partindo desse intuito, o meio digital se apresentou como um espaço possível para a difusão da Revista-Valise e, desta forma, ela foi inserida no Sistema Eletrônico de Editoração de Revistas (SEER)' e obteve seu cadastro e número de ISSN. O sistema SEER proporcionou certas diretrizes para a revista, tais como a clareza dos objetivos e a estrutura necessária para a efetivação da avaliação cega por pares, que garante imparcialidade na seleção dos trabalhos para publicação e transparência nas decisões editoriais. Desta forma, as submissões de artigos são realizadas através do

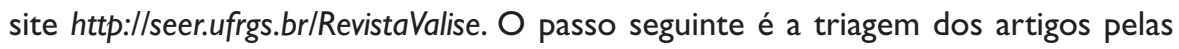
editoras, que encaminham cada um deles, sem identificação, para dois avaliadores, sejam eles membros do Conselho Editorial da revista ou pareceristas ad hoc. Quando necessário, uma terceira avaliação é solicitada.

Para a composição do Conselho Editorial pensamos, sobretudo, na abrangência de atuação, convidando pesquisadores atuantes no campo das Artes Visuais e afins, de diferentes universidades do país, com o objetivo de intensificar a troca de experiências. Enviamos, do mesmo modo, convites aos avaliadores ad hoc, no momento da distribuição dos artigos. É importante destacar a resposta positiva dos conselheiros e pareceristas ad hoc solicitados a participar da Revista-Valise, que possibilitou que o projeto da revista, desde o seu primeiro número, fosse levado adiante.

Ainda com a intenção de promover discussões, a Revista-Valise, juntamente com - Grupo de Pesquisa Veículos da Arte (CNPq-UFRGS), realizou em outubro de 201 I - Seminário de Pesquisa do PPGAVIUFRGS - O Espaço de Publicação no Processo Artístico. ${ }^{2}$ Tal evento visou promover uma reflexão acerca das formas de concepção e difusão do pensamento artístico e teórico através dos meios editoriais, trazendo assim ao debate a problemática da veiculação da arte contemporânea.

\section{Periódicos científicos em artes visuais e pesquisa discente}

Os periódicos científicos são espaços que armazenam e fazem circular a produção de conhecimento. Segundo Gruszynski (2008, p. 3), o surgimento das revistas científicas na segunda metade do século XVII carregava a esperança de que
0 Sistema Eletrônico de Editoração de Revistas (SEER) é uma adaptação brasileira do sistema Open Journal Systems (0JS) da British Columbia University, realizada pelo Instituto Brasileiro de Informação em Ciência e Tecnologia (IBICT). Visa 0 armazenamento e acesso livre à informação científica, possibilitando pesquisas e trocas de metadados através do protocolo OAI-PMH - Open Archives Initiative Protocol for Metadata Havesting.

\section{2}

Com intuito de reunir e resgatar produções editoriais recentes de alunos $e$ ex-alunos do PPGAV/UFRGS, a mesa contou com a presença de Aline Dias, responsável pela publicação Cadernos de Desenho, de Danillo Villa, autor, juntamente com Elke Coelho, de Cartografias Cotidianas, e de Michel lózimo, com Estratégias expansivas: publicações de artistas e seus espaços moventes. 0 evento promoveu 0 lançamento e a distribuição gratuita das publicações mencionadas. 
o estabelecimento de um debate coletivo possibilitasse novas descobertas. Somase a isso a necessidade de formalização do processo de comunicação científica, a legitimação da produção e o reconhecimento de autoria e autoridade, o que "garante a memória da ciência, aponta seu grau de evolução, estabelece a propriedade intelectual, legitima novos campos de estudos e disciplinas, constitui-se em fonte para o início de novas pesquisas, dando visibilidade e prestígio aos pesquisadores entre um público altamente especializado, os seus pares" (ibidem, p. 4).

Considerando ainda a importância de divulgar e compartilhar os resultados das pesquisas, a veiculação da Revista-Valise, em particular, e de tantos outros periódicos científicos, em geral, através da internet possibilita agilidade nos fluxos editoriais, bem como amplia a distribuição e visibilidade das edições, de acesso livre e gratuito. São estabelecidas, assim, condições para a intensificação dos diálogos, que podem se estender para além do espaço da revista, entre autores e leitores. No caso específico da pesquisa discente, como os pesquisadores estão em fase de formação, tal retorno pode significar maior qualificação e enriquecimento da experiência de pesquisa.

Um dos grandes desafios que a universidade contemporânea enfrenta, tem sido a difusão e o intercâmbio do conhecimento produzido pelo seu corpo discente. A experiência assimilada pela realização das três primeiras edições da Revista-Valise nos indica que hoje é imprescindível a formação de grupos que se reúnam por afinidades intelectuais e que estejam dispostos a interagir em um meio que contribua para a disseminação pública dos resultados gerados pela pesquisa realizada nos programas de pós-graduação. $O$ desejo de estabelecer um livre e profícuo intercâmbio de ideias entre diferentes núcleos acadêmicos poderá representar novos rumos e desafios para a reflexão, desafios esses que merecem ser enfrentados.

\section{Considerações finais}

A Revista-Valise, ao proporcionar um espaço qualificado de publicação para pesquisadores pós-graduandos ou pós-graduados, procura ir além de um sistema de arquivamento digital. Como editoras, buscamos ativar discussões e promover a possibilidade de intersecção entre práticas e projetos distintos no campo das Artes Visuais e afins. A Revista-Valise se coloca como um espaço de fomento à pesquisa ao propor o encontro da produção artística e teórica atual e ao contribuir para a interlocução entre diferentes instituições e colaboradores independentes, ampliando assim a divulgação dos resultados de pesquisa. 


\section{REFERÊNCIAS}

BRITES, Blanca;TESSLER, Elida (orgs.). $O$ meio como ponto zero: metodologia da pesquisa em artes plásticas. Porto Alegre: Ed. da Universidade/UFRGS, 2002.

CARROL, Lewis. Alice no país do espelho. Porto Alegre: L\&PM, 2008.

GRUSZYNSKI, Ana Cláudia; GOLIN, Cida; CASTEDO, Raquel. Produção editorial e comunicação científica: uma proposta para edição de revistas científicas. Revista da Associação Nacional dos Programas de Pós-Graduação em Comunicação, E-compós, Brasília, v.l I, n.2, maio/ago. 2008. Disponível em: <http://www.compos.org.br/seer/index.php/e-compos/article/viewFile/238/274>. Acesso em outubro de $201 \mathrm{I}$.

$\Gamma$

\section{DANIELA PINHEIRO MACHADO KERN}

Professora no curso de Bacharelado em História da Arte e no Programa de Pós-Graduação em Artes Visuais, PPGAV/ UFRGS, da Universidade Federal do Rio Grande do Sul, UFRGS. Doutora em Letras e doutoranda em História (História, Ciência e Arte) pela Pontificia Universidade Católica do Rio Grande do Sul, PUCRS.

「了

\section{CLAUDIA ZIMMER DE CERQUEIRA CEZAR}

Artista e pesquisadora, licenciada em Artes Plásticas pela Universidade do Estado de Santa Catarina, UDESC. Doutoranda em Artes Visuais (Poéticas Visuais) pelo PPGAV/UFRGS. Integrante de grupos de pesquisa na UFRGS e na UDESC.

「」

\section{FERNANDA BULEGON GASSEN}

Artista e pesquisadora, com especialização em Arte eVisualidade pela Universidade Federal de Santa Maria, UFSM. Doutoranda em Artes Visuais (Poéticas Visuais) pelo PPGAV/UFRGS.

「I

\section{HELENE SACCO}

Professora dos cursos de Artes Visuais da Universidade Federal de Pelotas, UFPEL. Artista e pesquisadora, com especialização em Didática e Metodologia de Ensino Superior, pela Universidade do Extremo Sul Catarinense, UNESC. Doutoranda em Artes Visuais (Poéticas Visuais) pelo PPGAV/UFRGS.

\section{「」}

\section{MARINA BORTOLUZ POLIDORO}

Professora da Faculdade de Design do Centro Universitário Ritter dos Reis, UniRitter. Artista e pesquisadora, com graduação em Comunicação Social pela Universidade de Caxias do Sul, UCS. Doutoranda em Artes Visuais (Poéticas Visuais) pelo PPGAV/UFRGS.

「I

\section{VIVIANE GIL ARAÚJO}

Pesquisadora, professora no Centro Universitário Ritter dos Reis, UniRitter, nas áreas de arte, design e moda. Doutoranda em Artes Visuais (História, Teoria e Crítica) pelo PPGAV/UFRGS. 
